\title{
7 O impacto causado pela doença mental na família
}

| Ana Carla Moura Campos Hidalgo de Almeida'; Lujácia Felipes²; Vanessa Caroline Dal Pozzo

\section{RESUMO}

Após a reforma psiquiátrica o modelo de assistência ao portador de doença mental passou a incluir a família e buscou inserir o indivíduo na sociedade.

\section{Objetivo}

Identificar o impacto causado pela doença mental na família e a concepção da família acerca da doença mental.

\section{Metodologia}

Estudo qualitativo, exploratório e descritivo desenvolvido em um Centro de Atenção Psicossocial no Brasil, realizado com familiares de indivíduos com doença mental, utilizando entrevista semi-estruturada gravada.

\section{Resultados}

A falta de conhecimento e de informação sobre a doença são elementos que dificultam o tratamento, aumentando o sentimento de incapacidade e de desamparo por parte da família.

\section{Conclusão}

Cabe a enfermagem intervir com conhecimentos científicos sistematizados e orientações sobre o apoio à família.

\section{PALAVRAS-CHAVE: Família; Doença Mental; Enfermagem.}

\section{ABSTRACT}

After the reform psychiatric care model for mental patients now includes the family and tried to insert the individual in society.

\section{Objective}

To identify the impact of mental illness in the family and identify what the concept of family about the disease mental.

\section{Methodology}

Qualitative study, exploratory and descriptive developed a
Center for Psychosocial Care (CAPS) in Brazil. The study subjects consisted of five family members of individuals with mental illness, and collecting data was through semistructured interviews.

\section{Results}

Lack of knowledge and information about the disease are elements that make treatment more difficult, increasing the feeling of powerlessness and helplessness on the part of the family.

\section{Conclusion}

It is the nursing intervention with scientific and systematic guidance on family support.

\section{KEYWORDS: Family; IIIness; Nursing.}

\section{INTRODUÇÃO}

A doença mental surge como uma barreira que dificulta o contato do indivíduo com o ambiente em que está inserido, tornando-o alienado e na maioria das vezes privando-o de sua liberdade e da possibilidade do convívio com as pessoas. Para Espinosa (2000, p. 18), o transtorno mental pode ser entendido como uma alteração fisiológica ou orgânica e psicológica, ou ainda um desequilíbrio emocional causado por fatores externos ou internos.

Compreender a doença mental significa modificar e desconstruir ideologias, crenças e valores em relação a patologias mentais, utilizando princípios norteadores do processo de transformação institucional através da Reforma Psiquiátrica, Lei n. ${ }^{\circ} 10.216$ instituída em 06 de abril de 2001, que tem como proposta transformar o modelo assistencial de Saúde Mental através da construção de um novo estatuto social para pessoas portadoras de transtornos mentais respeitando os princípios fundamentais de cidadania (Murta, 2006).

A partir da década de 1970, ocorreram no País inúmeros casos de denúncias relacionados aos maus tratos de

\footnotetext{
1,2 Enfermeira, Professora de Enfermagem da Pontifícia Universidade Católica do Paraná - Campus Toledo (PUCPR - Toledo) Paraná - Brasil.

${ }^{3}$ Enfermeira, Estudante de Mestrado em Enfermagem no Instituto de Ciências da Saúde, Universidade Católica Portuguesa - Porto, vanessadalpozzo@ hotmail.com Submetido em 20-09-2011. Aceite em 16-12-2011.

Citação: Moura, A. C.; Almeida, C. H.; Dal Pozzo, V. C. (2011). O impacto causado pela doença mental na família . Revista Portuguesa de Enfermagem de Saúde Mental. 6, 40-47.
} 
pacientes em instituições psiquiátricas. Então ocorreu a necessidade de uma reforma em todo o sistema de assistência ao portador de doença mental, surgindo desta maneira um novo paradigma em relação à assistência psiquiátrica que propunha a inclusão do indivíduo portador de distúrbio mental na sociedade e no âmbito familiar.

A reforma não pretende acabar com o tratamento clínico da doença mental, mas eliminar a pratica da internação que é entendida como forma de exclusão social dos indivíduos com doenças mentais.

Partindo dessa necessidade, houve a implementação de instituições que propunham inserir pacientes portadores de doença mental que tinham permanecido internados por um longo período, assim como orientar e ajudar a restabelecer o vínculo com suas famílias, para tanto foi constituído o Centro de Atenção Psicossocial (CAPS).

A partir do movimento da Reforma Psiquiátrica surgem os Centros de Atenção Psicossocial (CAPS) e os Núcleos de Atenção Psicossocial (NAPS) que tinham a intenção de programar uma nova estratégia de trabalho através de mudanças no plano legislativo, assegurando a atenção no meio sociocultural do portador de transtorno mental (Rosa, et al. como citado em Ferreira, 2003, p.21).

Entende-se que a reforma procura resgatar a cidadania e o amparo dos doentes mentais e gradualmente consiga diminuir o uso dos manicômios, substituindo-os por serviços extra-hospitalares e, quando necessário, o internamento realizado em hospitais gerais, porém em alas reservadas a psiquiatria.

A proposta de desinstitucionalização do doente mental configura uma tentativa no sentido de diminuir o isolamento do cliente, como ocorria nos hospitais psiquiátricos. Sobre a ótica de uma assistência mais humanizada para com o indivíduo portador de doença mental deve-se levar em consideração todos os aspectos envolvidos no mesmo, como o enfrentamento da doença, convívio familiar e social.

Em meio a essas transformações e mudanças, a Reforma Psiquiátrica Brasileira procura oferecer aos indivíduos portadores de transtornos mentais direitos à cidadania, à liberdade e à privacidade, que são de certo modo prejudicados pelo internamento prolongado.

Nota-se a importância do atendimento prestado pelos CAPS's, no entanto há necessidade de se manter leitos psiquiátricos em hospitais de atendimento a assistência à saúde, no caso de surtos nestes pacientes. Concordando com o descrito acima, a preconização da assistência humanizada pautada na legislação entende que não há a necessidade de se oferecer uma ala psiquiátrica em um hospital geral, e sim cuidados de forma qualificada para esse segmento de clientela.
O preconceito e o despreparo de muitos profissionais da área da saúde, aliado aos recursos financeiros envoltos na adaptação de um hospital geral, contribuem com a demora da realização da reforma psiquiátrica de forma integral.

Embora seja percebido um desconforto em relação à qualificação dos profissionais no que diz respeito à assistência ao cliente com transtorno mental e compreendendo que o mesmo necessita de cuidados especializados, entende-se que essa dificuldade possa ser minimizada mediante o treino contínuo da equipe de saúde (Mion, 2003).

A autora ressalta ainda a questão financeira, pois se sabe que há insatisfação dos profissionais e dos serviços-médicos hospitalares em relação aos pagamentos dos serviços prestados pelo ao Sistema Único de Saúde.

Contribuindo com esse pensamento acredita-se que somente ocorrerão transformações na maneira de se conviver com o estigma da doença mental, quando houver um entendimento global da doença e no cuidado integralizado ao portador do sofrimento psíquico.

De acordo com Osório (1996, p. 27), “Os laços familiares, de uma forma ou de outra, continuam ocupando lugar de destaque na maneira com que a maioria de nós vê e vive o mundo; portanto falar de família é enfocar um conjunto de valores que dá aos indivíduos uma identidade e à vida um sentido".

Para este autor a família pode ser considerada como uma unidade grupal, que tem por objetivos a preservação da espécie, nutrir e proteger a descendência e ainda fornecerIhes condições para aquisição de suas identidades pessoais, transmissão de valores éticos, estéticos, religiosos e culturais.

Reafirmando, Almeida (2008, p.27) escreve que a família é reconhecida como a instituição que auxilia a vivência do indivíduo em sociedade, pois nela se formarão as novas gerações de cidadãos e se darão as primeiras experiências de relacionamentos. Diante disso é preciso estimular uma vivência saudável entre pais e filhos mediante o diálogo, a troca de experiência, de afeto, e a convivência entre seus membros.

O entendimento e a aceitação da doença mental por parte da família se tornam um elemento de extrema importância na reabilitação do individuo com doença mental.

Entende-se que essa angústia é passível ate mesmo de inconformidade, uma vez que muitas das famílias não se sentem preparadas para cuidar de seus entes portadores de alguma doença mental e necessitam de auxilio para desempenhar o papel de cuidador, visando conseguir atender os cuidados integrais do mesmo. 
A família pode ser entendida de uma forma mais tradicional do que é considerada na atualidade, dessa maneira as transformações ocorreram devido a maior intimidade entre seus membros, assim nas relações entres as gerações e nas variáveis externas incorporadas à família (Petzold, 1996).

Em relação à concepção que a família tem sobre a doença mental pode-se perceber que algumas dificuldades de entendimento da doença mental, bem como da instabilidade afetiva, fatores estes que entendem que o sofrimento mental possui como característica a cronicidade e incurabilidade desta doença, tais situações mostram que o familiar tem pouca compreensão sobre a sintomatologia e as mudanças de comportamento do sujeito em sofrimento mental, o que se deve, talvez pela falta de esclarecimento acerca da doença.

Embora alguns estudos mostrem que a convivência da família altera os costumes e hábitos do ser humano, entende-se também que a existência de um doente mental pode desestruturar a rotina da família, exigindo da mesma uma demanda de atenção para com o individuo doente. Nesse sentido cada integrante que constitui a família passa a adquirir um papel e significado próprio para conseguir administrar o novo cotidiano da vida familiar.

Deve-se levar em consideração as sobrecargas que a família passa em decorrência com o doente mental, podendo classificá-las como financeiras, nas rotinas familiares, como doença física ou emocional e as alterações das atividades de lazer e relações sociais.

Para Miles et al (1982 como citado em Ferreira, 2003, p. 27) a família ao deparar-se com a doença mental apresenta três formas de abordagens: o encobrimento, o ocultamento da doença do meio social e a normalização, prosseguindo com as atividades normais, encobrindo a realidade e a dissociação afastando-se do convívio da sociedade a fim de evitar futuros aborrecimentos.

"O cuidado oferecido deve respeitar e acolher a diferença do psicótico, ele deve ser percebido como um sujeito humano e não como um sintoma a ser debelado; além disso, o exercício da ousadia, da criatividade e da alegria deve estar sempre associado à atividade terapêutica." (Teixeira, 1999).

Para o autor citado, o enfermeiro esta cada vez mais atuante e consciente de seu novo papel e tem condições de explorar diversas modalidades terapêuticas no desempenho do exercício profissional.

Cabe aos profissionais da área da saúde, em especial a enfermagem que trabalha na área psiquiátrica, informar, esclarecer não somente aos parentes do indivíduo portador de doença mental, mas também a sociedade, para que se possa enfim contribuir para a diminuição de estigmas do passado que ainda atualmente atinge os portadores de doença mental, bem como seus familiares.

\section{OBJETIVOS}

Têm-se como objetivo geral desse estudo retratar o impacto causado pela doença mental na família e como específico identificar qual a concepção da família acerca da doença mental, assim como verificar quais estratégias que a família utiliza para enfrentar a doença mental.

\section{JUSTIFICATIVA}

De encontro com esta nova política da saúde mental, entendese que são necessárias mudanças no atendimento do doente e de sua família e na compreensão dos sentimentos envoltos no portador de transtorno mental.

Nesse sentido, a enfermagem pode contribuir com o cuidado humanizado e integralizado, visando não apenas o paciente, mas também a família do mesmo.

Com o entendimento da nova conduta do tratamento para psicóticos oferecidos pelo SUS (Sistema Único de Saúde), compreende-se que a família exercerá papel fundamental para viabilizar a reabilitação do paciente, para que se possa estabelecer o convívio social.

Entender as angústias que os parentes enfrentam diante dessa nova realidade e se há qualificação dos mesmos para oferecer os cuidados necessários que o portador de doença mental precisa, é de extrema relevância não somente para os profissionais de saúde, mas também para a sociedade.

O resultado deste retato poderá ajudar a enfermagem psiquiátrica com conhecimentos dos sentimentos e expectativas dos familiares para com essa transformação.

Desta forma poder-se-á construir um plano de orientações que ofereça suporte tanto emocional quanto de cunho cientifico para a qualificação ao atendimento que a família prestará aos portadores de doença mental.

\section{METODOLOGIA}

O presente estudo é descritivo, exploratório de natureza qualitativa, que conforme Minayo (2002, p.21) "Trabalha com um universo de significados, crenças, valores e atitudes, o que corresponde a um espaço mais profundo das relações, dos processos e dos fenômenos que não podem ser reduzidos à operacionalização de variáveis".

Teve como local para a realização da pesquisa um Centro de Atenção Psicossocial situado em um Município do Oeste do Paraná cuja organização possui Programa de Saúde Mental coordenada por uma enfermeira. Foram incluídos cinco 
familiares indicados pelo próprio CAPS que concordaram em assinar o termo de consentimento livre e esclarecido.

A pesquisa aconteceu após o parecer favorável do Comitê de Ética, no período de agosto de 2008 até janeiro de 2009. Foi utilizada a entrevista semi-estruturada gravada que, após análise do material, foi transcrita na íntegra. As respostas obtidas das entrevistas foram agrupadas e analisadas conforme a sua similaridade, respeitando a metodologia de análise de conteúdo. Os dados foram analisados por meio da análise de conteúdo, e os familiares identificados como (F01), (F02), (F03), (F04) e (F05).

\section{RESULTADOS}

Inicialmente foram requisitados dez familiares para serem entrevistados, contudo apenas cinco familiares concordaram em participar da mesma.

Dos cinco familiares participantes da pesquisa, quatro eram do gênero feminino e um do gênero masculino, a faixa etária variou de 43 a 57 anos, quanto ao estado civil todos eram casados, em relação ao nível de escolaridade, dois tinham o terceiro grau incompleto, dois o segundo grau completo e um o primeiro grau incompleto, quanto às condições de moradia todos possuíam casa própria e quanto a renda variava de 02 a 03 salários mínimos.

Através da análise do material coletado, pode-se obter que os participantes entendiam a patologia mental como uma doença onde há fuga da realidade, assim o processo de aceitação da doença pelos familiares se configurou como algo inesperado e difícil.

Após a aceitação da doença os integrantes do grupo familiar utilizam-se do diálogo e paciência como estratégia de convivência com o doente mental e relataram também sobre a falta de informação e a pouca proximidade com a equipe de saúde. Mencionam sobre a importância do uso da medicação e internação nos momentos críticos como elementos para melhorar a qualidade de vida do portador de transtorno mental e o convívio com o mesmo.

\section{DISCUSSÃO}

Em resposta sobre o entendimento da doença mental, construiu-se a seguinte temática:

\section{Doença em que há fuga da realidade}

A doença mental demonstra uma conotação diferente em relação á outras doenças por ser pouco difundida e cercada de muitos mitos. Conforme Townsend (2002, p.21) "são distúrbios psiquiátricos graves caracterizados pela presença de delírios ou alucinações e o distúrbio do funcionamento interpessoal e da relação com o mundo externo".

Desse modo, vale mencionar como se torna difícil o entendimento de uma doença onde o individuo em questão tem momentos de alucinações. Para Kaplan et al. (2003, p.03) "é tido como significado tradicional do termo psicose a perda do teste de realidade e comprometimento do funcionamento mental, expressos por delírios, alucinações, confusão e comprometimento da memória”. Assim como mostra os pesquisados:

"É uma pessoa que não é que, não ta agindo com a realidade que tenta coisa, ta totalmente fora da realidade". (F01).

"Doença mental para mim é um eu vou falar no caso do meu filho. que é esquizofrênico ele normalmente foge da realidade(...)".(F03)

“(...) Ela não tem decisão própria, você tem que tá atento a todo o momento com ela e é que nem eu disse tem que ficar ligando na casa dela, porque ela tem momentos de lucidez, mas é pouco e outros são de delírios e alucinação (...)". (F04)

A família necessita ter conhecimentos específicos e claros sobre a doença e saber conviver com o mesmo durante o período de alucinações, no entanto, cabe ressaltar que em diversas vezes justamente nos momentos de alucinações que o portador de doença mental pode ser extremamente agressivo.

As categorias formadas abaixo resultam da recepção da noticia de ter um portador de doença mental na família:

\section{Algo inesperado para os familiares}

Em resposta a questão indagada aos familiares de pacientes portadores de doença mental, sobre como foi receber a notícia de ter um portador desta doença na família, possibilitou perceber em alguns dos relatos dos sujeitos entrevistados sentimento de indignação, algo difícil de se aceitar, enfim uma experiência nova.

Conforme o autor Góes (2004, p. 05) "quando ocorre a confirmação de que o familiar tem distúrbio mental tal situação causa um trauma psíquico originando grande inquietação e angustia nos pais e família tornando-se um choque ao inesperado.". Estes sentimentos podem ser observados em algumas respostas.

"Pra mim foi bem difícil na época eu tava grávida de sete meses foi um baque (...)". (F02)

"Olha eu fiquei chocada. Agente fica sem chão(...)". (F04) 
"Pra mim foi um experiência nobre e terrível ao mesmo tempo, porque eu tava só acostumado com doenças físicas e não mentais (...)". (F05)

“(...) Primeiro foi procura sabe o que seria essa doença e depois veio o próximo passo da aceitação da doença (...) bastante difícil (...)". (F03)

Contribuindo com a idéia do autor, e em base das respostas dos participantes deste estudo pode-se citar que as famílias estão acostumadas em seio familiar com pessoas sem alteração mentais assim oferecendo continuidade as expectativas para o futuro, muitas vezes planejadas quando a criança ainda na fase de desenvolvimento no útero da mãe.

A partir deste diagnóstico se modificam os planos para o futuro, a vida de todos os entes da família requer uma readequação, visto que alguns dos familiares relutam em aceitar o sofrimento psíquico, aliado a este sentimento de recusa têm - se os estigmas e preconceitos atribuídos ao doente mental pela sociedade.

Contribuindo com este pensamento as autoras Zanetti e Galera (2007, p.389) citam: “...o sofrimento da esquizofrenia é visto como algo inesperado, que aconteceu de repente sendo comparado a um choque pela família. O desenvolvimento dos filhos, aparentemente saudáveis, não permitia, aos pais, imaginarem que os mesmos viessem sofrer uma doença que causasse tantas restrições como causou."

Através da coleta de dados para este estudo foi possível vivenciar um pouco da experiência do cotidiano dos familiares de portadores de doença mental, observando assim os seus sentimentos e suas expectativas no tratamento dos mesmos.

Pode-se falar que não é fácil esta nova forma de vida que os mesmo foram submetidos a se readequar, devido às necessidades de seus familiares.

Entende-se que a sociedade necessita ter maior conhecimento sobre a patologia mental a fim de diminuir a descriminação imposta pela mesma, visto que apesar da reforma psiquiátrica, os doentes mentais ainda carregam estigmas de loucos, sendo necessário a privação do mesmo para não comprometer o convívio na sociedade.

Vale mencionar que os portadores de doença mental são capazes, e devem desenvolver as atividades de sua vida normal, é claro com orientações e acompanhamento de seus familiares e equipe de saúde, fazendo com que os mesmos se percebam capazes e valorizados.

\section{Aceitação da doença pelos familiares}

Percebeu-se em alguns dos relatos dos sujeitos entrevistados a aceitação da doença visando buscar informações sobre esta nova patologia que acomete seu familiar para assim dar inicio ao tratamento e reestruturação do modo de vida dessas famílias.

Conforme Spadini et al (2006, p.126), "o reconhecer e aceitar a doença é entendido como necessário e essencial para a melhora da qualidade de vida de pacientes e familiares".

Corroborando com as idéias das autoras vale mencionar, com a aceitação inicial da doença pelas famílias fica mais fácil para que o portador da doença mental aceite, construindo assim um caminho mais fácil a fim de buscar ajuda junto aos centros de atenção psicossocial, visando com isso trabalhar as necessidades do paciente, bem como de seus familiares, com orientações corretas sobre a doença e o proceder do tratamento e suas limitações concomitante a reinserção a vida social.

Para Cavalheri et al (2002 como citado em Nasi, C., Stumm, L. K., Hildebrandt, L. M., 2004, p.04): “Quando a família possui um membro com uma doença mental, toda ela acaba mobilizando-se inteiramente. Independente de ser orgânica ou mental, o desgaste é agravado quando se trata de uma doença de duração prolongada, com freqüentes casos de agudização de sintomas e quando é considerada incapacitante e estigmatizante."

Concordando com o pensamento do autor, é possível retratar que o acompanhamento dos familiares e o entendimento dos mesmos, sobre tratamento desta doença em diversas fases são de extrema importância, pois se trata de uma doença de sinais e sintomas diferentes das quais estão acostumados.

Essa doença acarreta em desgaste tanto para o portador quanto para sua família, pois acontecem episódios em que os doentes entram em crise onde se destaca agressividade.

Diante disso muitos portadores da doença querem abandonar o tratamento, é neste momento que a aceitação da família deve falar mais alto, intervindo na situação, deixando clara a importância do mesmo para todos os entes da família, e aconselhar a não desistência do tratamento, mostrando assim que ele é amado por sua família e todos contribuem para recuperação do doente psíquico.

Segundo a autora Nasi et al. (2004, p.03), "A família é um suporte básico para a vida de qualquer pessoa, mas para os doentes mentais psicóticos ela possui especial importância, pelo fato desses sujeitos, na maior parte das vezes, necessitarem de cuidados e acompanhamentos dos membros do grupo familiar".

Colaborando com a aceitação da doença pelos familiares podem-se citar alguns dos relatos das entrevistas.

"Minha mãe já é assim desde que eu nascientão praticamente à gente convive com isso a vida toda entende". (F01) 
"Fui procura sabe o que seria essa doença e depois, daí veio o passo, o próximo passo de aceitação da doença”. (F03)

Com os dados da entrevista em mãos, podemos mencionar que o primeiro passo para melhorar a qualidade da assistência psiquiátrica prestadas pelos familiares aos entes acometidos pela doença mental, é a questão de aceitar que seu filho ou outro ente da família agora necessita de uma atenção especial, o segundo passo é buscar ajuda junto aos centros de atenção psicossocial, visando o entendimento da doença e o tratamento adequado para mesma.

Ao serem entrevistados os familiares sobre quais estratégias a família utiliza para realizar o cuidado do individuo portador de doença mental, obteve-se as seguintes temáticas:

\section{Diálogo e paciência como estratégia de convivência com o doente mental}

Os pesquisados foram unânimes ao mencionarem que utilizam da paciência como meio facilitador para o convívio familiar.

"Paciência a gente tem que ter paciência pôr que falam ou eles num entendem por motivo da doença ou eles querem ter razão. Então tem que ter paciência i levando. A gente sofre muito... se incomoda". (F02)

"Quando eles tão muito alterado, eu pego e saio vou andar caminho vou andar pela estrada, saio em lugares, vou conversar com alguém daí quando ele já ta mais calmo né, então agente viu que é tudo assim, sai deixar ele quieto não retrucar nada por que quanto mais você questionar com ele pior ele fica, mais ele se altera então agente busca pega sai ou puxa outro assunto com ele que faça esquecer aquilo que ele ta falando". (F04)

Para Pereira e Pereira (2003, p.97): "As hostilidades, os comentários críticos o intenso envolvimento pessoal podem ser fatores preditivos de recaídas, de reagudização dos sintomas. Uma redução na intensidade de expressão destes fatores pode possibilitar uma maior estabilidade emocional, contribuindo para a diminuição dos conflitos que circulam no interior da vida familiar."

Por tudo, a utilização do exercício da paciência auxilia na diminuição destes conflitos caracterizados pelo desgaste da convivência, pela agressividade que em grande parte da doença mental e demais sintomas conflituosos gerados pelo próprio processo da doença mental, na rotina familiar.

\section{Uso da medicação e internação para melhorar a qualidade de vida}

Durante o convívio familiar surgem estratégias que facilitam e proporcionam melhorias na qualidade de vida no seio da família.
"Mais a gente procura assim fazer, fazer com que ele tenha uma qualidade de vida melhor, com a volta da medicação eles tem condição de levar uma vida não vou dizer totalmente normal, mas controlável ih dessa forma que a gente procura né, pra que leve a vida pra frente. (F03)

Nessa categoria entende-se que a medicação assim como o uso de internação quando o doente mental se torna extremamente agressivo torna-se um meio facilitador da convivência.

Assim como mostra os autores Duarte et al. (2007, p.06): "O uso de psicofármacos é eficiente, principalmente nos momentos de agudização dos sintomas e constitui um importante elemento terapêutico, embora complementar ás terapias individuais e ás em grupos."

Cabe aos profissionais de saúde orientar em relação ao uso correto dos medicamentos e a importância da internação, quando a agressividade do portador de doença mental atribui risco eminente aos demais membros da família.

Os entrevistados ao serem indagados sobre o convívio com o membro familiar que tem sofrimento psíquico e sobre suas dificuldades e facilidades, neste processo, foram construídas as seguintes categorias:

\section{Informação e proximidade com a equipe de saúde sobre a doença como forma de melhorar o cuidado}

Em relação ao entendimento sobre a doença mental os participantes mencionaram a necessidade de mais informações sobre a mesma. Assim surgiu a categoria acima que refere ao trabalho em equipe, que envolvem órgãos desde a atenção primaria de saúde á hospitais manicomiais.

"Eu procurei identificar quais seriam as conseqüências dessa doença mental, daí comecei a aprender junto com eles com os médicos e com os psicólogos do posto mesmo de saúde publica e consegui identificar". (F05)

Percebe-se o quão fundamental é a informação correta sobre a doença mental ao portador e seus familiares.

Dessa forma corroborando com a autora Romagnoli (2006, p.311) "as famílias quando chegam, a saber, o nome da doença mental não sabe o que ela significa". Nota-se o despreparo das famílias envolto em um sentimento de solidão e desamparo por falta do conhecimento da doença.

Em relação ao sentimento de desamparo por parte dos familiares com a equipe de saúde os autores Nasi et al. (2004, p.07) dispõe "a equipe de saúde, freqüentemente, só atenta para o que esta acontecendo com a pessoa acometida pelo adoecer psicótico e com sua medicação".

"A gente não entende muita coisa é meio difícil, mas já ta com tantos anos que venho acompanhando é que uma 
coisa, uma coisa que pra muitos é não consegue entender, mas é difícil". (F02).

Conforme Nasi et al. (2004): "Tais falas demonstram que o familiar tem pouca compreensão sobre a sintomatologia e as mudanças de comportamento do sujeito portador de doença mental, o que se deve talvez pela falta de esclarecimento acerca da doença Moreno et al. (2000, p.04 como citado em Rabelo et al. 1998), coloca que o diagnóstico da doença é muito valorizado pelo familiar, mas, na maioria das vezes ele não possui o entendimento da patologia propriamente dita. Cabe ressaltar que as orientações a respeito da doença e de como conviver com o doente mental, deve ser fornecidas pela equipe de saúde tanto ao paciente quanto ao familiar."

\section{Privação da vida social da família}

As Famílias que possuem entre seus membros um sujeito acometido por um sofrimento mental chegam a alguns casos restringir-se da participação de vida social, muitas vezes pelo preconceito existente na sociedade e também porque precisam mudar determinados hábitos acerca do relacionamento familiar, pois o doente mental precisa ser cuidado e acompanhado por alguém ininterruptamente.

Tais falas demonstram como os familiares se sentem em relação privação da vida social e de lazer.

"As dificuldades é o seguinte... Que tu num se acha, não se sente bem sai com ele, ele tem aquelas atitudes diferentes ele tem... Num tem mais aquele comportamento pra sai num almoço, num jantar na sociedade, é difícil." (F02).

"As dificuldades é o que eu tenho que viver em casa, eu não posso sair (...) Não posso trabalhar fora eu tenho que estar às vinte e quatro horas pra cuidar dele, tem que dar medicação três vezes ao dia, a gente não pode viajar... Tem que levar ele e se levar em vez de descansar volta mais estressado ainda(...). Então se for pra ir tem que deixar com alguém ou viajar na época que ele ta internado, quando ele interna daí a gente da uma descansada uma arejada na cabeça, quando volta pra casa segue de novo continua então é o único jeito mesmo da gente poder descansar "(FO4)

A distância entre a família e o corpo social pode ser exemplificada pela ausência em festas e eventos, a diminuição do número de visitas a amigos e parentes. Os familiares com contato mais próximo ao individuo em situação de sofrimento mental usualmente não dispõem de tempo nem espaço para manter outros relacionamentos, envolvem-se apenas com o que diz respeito à doença mental, tornando o vínculo sobrecarregado de cobranças e exigências em relação a eles mesmos e a pessoa de quem cuidam Miles et al. (1982 como citado em Pedoraro et al. 2006, p. 570).

Além do mais, os estudos de Koga e Furegato (1998 como citado em Nasi et al. 2004, p.04) tratam das sobre cargas que a família passa em decorrência da convivência com o doente mental, classificando-as como financeira, nas rotinas familiares, como doença física ou emocional e alterações das atividades de lazer e relações sociais.

\section{CONSIDERAÇÕES FINAIS}

A pesquisa propôs retratar o impacto causado pela doença mental na família, identificar qual a concepção da família acerca da doença mental e verificar quais estratégias que a família utiliza para enfrentar a doença mental.

A enfermagem compreende um elemento fundamental para otimizar o tratamento da doença de sofrimento psíquico. Entender a angústia por parte dos familiares é fundamental para uma boa relação entre o profissional de enfermagem e os envolvidos assim como o doente.

A falta de conhecimento e o entendimento correto sobre a doença são elementos que dificultam o decorrer do tratamento, além de aumentar o sentimento de incapacidade e de desamparo por parte da família.

Cabe a enfermagem intervir com informações acerca da doença, o uso correto das medicações envolvidas que acaba por se tornar um grande aliado nas estratégias da convivência familiar.

Para finalizarmos é necessário ressaltar a importância da família na assistência ao portados de doença mental, e também a necessidade de cuidado e apoio por parte da equipe de saúde e principalmente da enfermagem com o familiar que na maioria das vezes encontra-se desgastado e desamparado.

\section{REFERÊNCIAS BIBLIOGRÁFICAS}

Almeida, H. (2008). A enfermeira no contexto da educação sexual dos adolescentes e o olhar da família. Disponível em: <http://dspace.c3sl.ufpr.br/dspace/bitstream/1884/14404/2/ capa.pdf>. Acesso em: 15 out. 2009.

Cavalheri, S. C. (2002). Acolhimento e orientação à família. Mesa Redonda. Importância da família na saúde mental, Disponível em: <http://www.webartigos.com> Acesso em: 20 set. 2009 .

Duarte, C.L.M.; Souza, J.; Kantorski, P.L. \& Pinho, B.L. (2007). Diferentes abordagens à família em saúde mental presentes na produção científica da área. Rev. Min. Enferm; v. 11, n. 1, p. 66-72, jan/mar. Disponível em: <http://bases. bireme.br> Acesso em: 03 out. 2009.

Espinosa, A. (2000). Psiquiatria ED. Mc Graw-Hill: Rio de janeiro. 
Goes, F. (2006). Um encontro inesperado: os pais e seu filho com deficiência mental. Psicol. cienc. prof. v.26, n.3, p. 450461, set. Disponível em: <http://pepsic.bvs-psi.org.br/scielo. php?script=sci_arttext\&pid=S1414-98932006000300009 \&lng=pt\&nrm=iso>. ISSN 1414-9893> Acesso em: 19 out. 2009.

Kaplan, H., Sadock, B. \& Greebb, J. (2003). Compêndio de psiquiatria: ciência do comportamento e psiquiatria. 7. ed. Porto Alegre: Artmed.

Miles, A. (1982). O doente mental na sociedade contemporâneo. Rio de janeiro: Zahar.

Minayo, M. (2002). Pesquisa social: teoria, método e criatividade. $20^{\mathrm{a}}$ ed. Petrópolis: Vozes.

Mion, J. Z. Leitos (2003). Psiquiátricos em Hospital Geral: visão de profissionais que atuam em hospital geral. Revista Eletrônica de Enfermagem, v. 5 n.1, Disponível em: <http:// www.revistas.ufg.br/index.php/fen> Acesso em: 06 out. 2009.

Murta, G. F. (2006). Saberes e práticas: guia para ensino e aprendizado de enfermagem. $2^{a}$ ed. rev. São Caetano do Sul: Difusão Editora, 1 v. 460 p.

Nasi, C. S., Lílian, K., \& Hildebrandt, L. M. (2004). Convivendo com o doente mental psicótico na ótica do familiar. Revista Eletrônica de Enfermagem, v. 6, n. 1, p.59-67, Disponível em: <www.fen.ufg.br> Acesso em: 19 nov. 2009.

Rosa, L. (2003). Transtorno mental e o cuidado na família. São Paulo: Cortez.

Osório, L.,C. Família hoje. Porto Alegre: Artes. Médicas, 1996.
Pereira \& Pereira Jr. (2003). Transtorno mental: dificuldades enfrentadas pela família. Rev. esc. enferm. USP, São Paulo, v.37, n. 4, dez.. Disponível em: <http://www.scielo.br/scielo. php?script=sci_arttext\&pid $=$ S0080 -62342003000400011 . . Acesso em: 24 set. 2009.

Petzold, M. (1996) The psychological definition of "the family". Em M. Cusinato (Org), Research on family resources and needs across the world. Milão: LED/Edecioni Universitarie.

Romagnoli, R.C. (2006). Famílias na Rede de Saúde Mental: um breve estudo esquizoanalítico. Psicologia em Estudo, Maringá, v. 11, n. 2, p. 305-314, mai./ago. Disponível em: <http://www.scielo.br/pdf/pe/v11n2/v11n2a08.pdf>. Acesso em: 22 set. 2009.

Spadini, L. \& Souza, M. (2006). A doença mental sob o olhar de pacientes e familiares. Rev. esc. enferm. USP, v. 40, n. 1 , p. 123-127, Acesso em: 04 set. 2009.

Teixeira, O. (1999). Do asilo ao hospital-dia: considerações sobre a atenção psiquiátrica e saúde mental. Saúde em foco: informe epidemiológico em saúde coletiva.

Townsend, M.C. (2002). Enfermagem Psiquiátrica: conceito de cuidados: $3^{a}$ ed. Rio de Janeiro: Guanabara Koogan S.A.

Zanetti, A. \& Galera, S. (2007). O impacto da esquizofrenia para a família. Revista Gaúcha Enfermagem, v. 28, n. 3, p. 385-392. Disponível em:<http://www6.ufrgs.r/seermigrando/ ojs/index.php/RevistaGauchadeEnfermagem/article/ view/4689/2596>. Acesso em: 19 out. 2009. 